Education $\mid$ Marie C. Paretti, Julie Dyke Ford,

\& Training Susannah Howe \& Daria Kotys-Schwartz

\title{
Engineering capstone courses help students transition from school to work
}

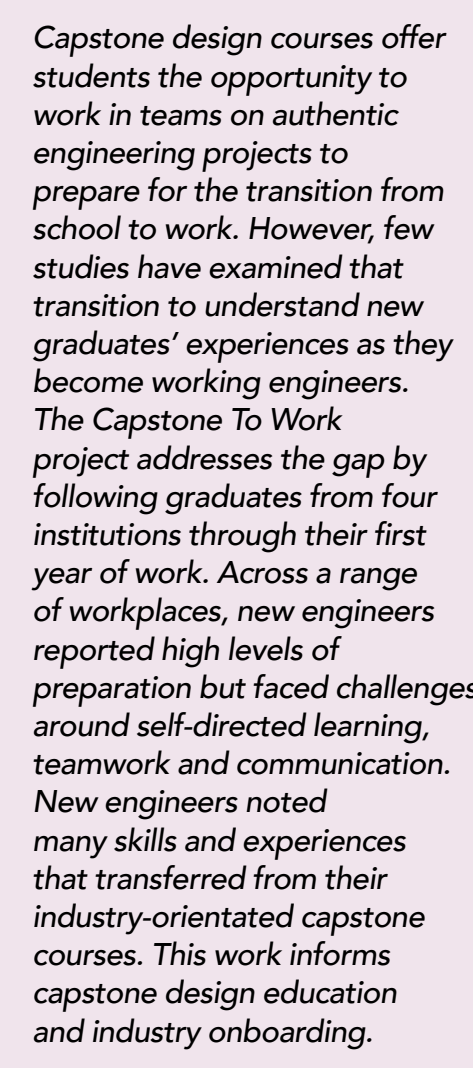

$M$

I countries undergo capston

design courses at the end of their

undergraduate experience. Similar

to clinical experience for medics and

lawyers or bachelors' theses in some

offer

to bridge school and work These

courses are a place where students

bring together knowledge from

previous courses plus new learning in

application to industrial projects for

external clients, while simultaneously

expanding students' professional skills.

Since their inception in the 1980s,

capstone design courses have become

ubiquitous because of their potentia

to enhance students' professional

preparation in engineering. They often

take the form of a semester or year-long team project sponsored by external

Despite a nraustry and govemment.

captie a growing andy gov research into capstone courses - investigating the types - few studies have
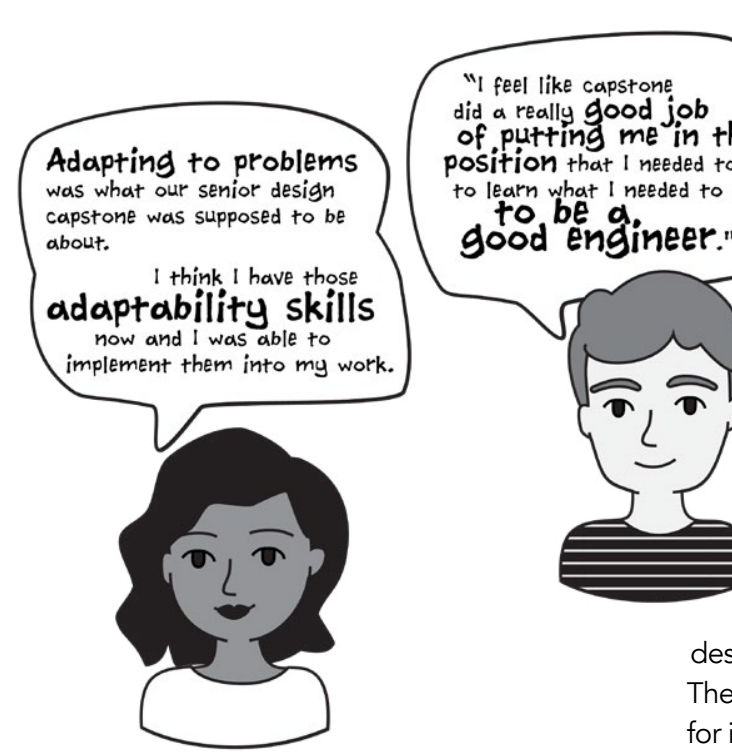
journeys from capstone design

\section{CAPSTONE TO}

WORK RESEARCH

The "Capstone to Work" on what activities new employees engage in, how prepared they feel for they employ to meet these challenges, and, in particular what aspects of capstone design transfer to their early careers. The research has major implications and industry on-boarding practices to smooth the transition and ensur Prepard and proficient new employees.

Led by Marie Paretti at Virginia Tech longside Julie Ford (New Mexico Tech), Susannah Howe (Smith College) f Colra Ko w recruited 120 graduates from two different years at four institutions as they completed project-based capston design courses. The capstone courses at these institutions were consistent with national trends in terms of course structure and teaching. Every participan was interviewed at the end of the capstone design course, and also after 3,6 and 12 months of being in the workplace. During their first 12 weeks of work, the graduates also recorded experiences in twice-

\section{'WW ENGINEERS' EXPERIENCES} Analysis of the extensive interview and survey responses provides a rich hifting from the role of student to th of new engineer.

Tasks and Activities

In their first three months, the new engineers were involved with many different tasks and activities, the most fequent of which included team meetings, project planning, design calculations, CAD modelling, and report writing. They also spent significant time learning new information associated with their organisation and industry. These activities are common that these design courses, suggesting that these courses are successfully Formal training also occurred for some
Pathway to impact for the Capstone to Work (C2W) project.

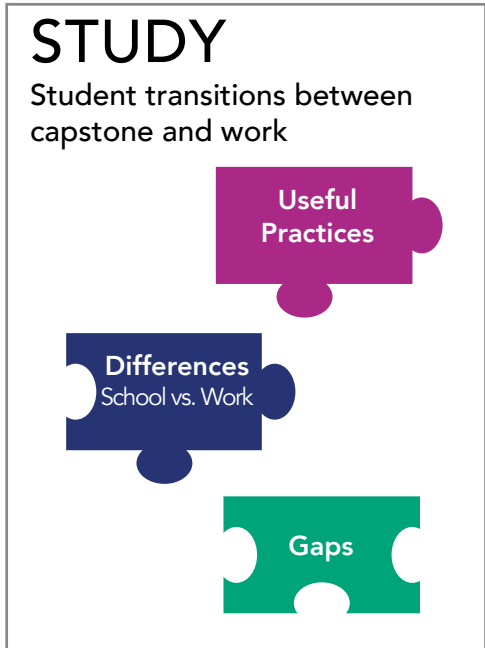

new engineers during their first month on the job.

Perceived Preparedness general, the new engineers felt wellI

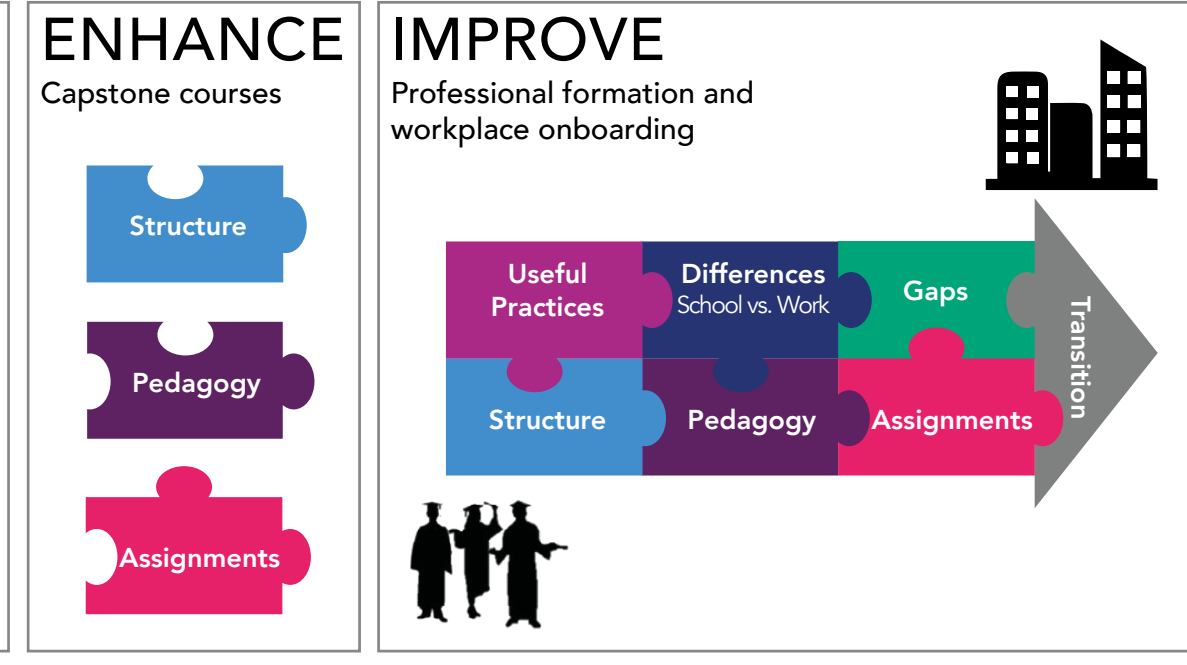

of work were not free from challenges. More than $90 \%$ of the new engineers self-directed learning (perticularly bck of knowledge and time management) and teamwork and communication. Almost all participants reported

New employees are expected to be self-directed learners, able to quickly grasp technical concepts as well as a company's culture and goals.

all four institutions reported feeling more prepared on average for work the longer they were on the job. Notably, many participants also reported receiving sedback on trem pelce iso contertulised. Women repoted the same average growth in perceived preparedness as men, but reported statistically significantly lower absolute values in months 2 and 3 when asked to ate themselves on a numeric scale (1-10). That is, women's sense of preparedness increased at the same rate as men, but they scored themselves lower numerically. These findings are consistent with prior research showing that womentypically underrate their performance on tasks wile men overrate their performance.

Challenges

hile participants reported feeling Wrepared for workplace tasks and

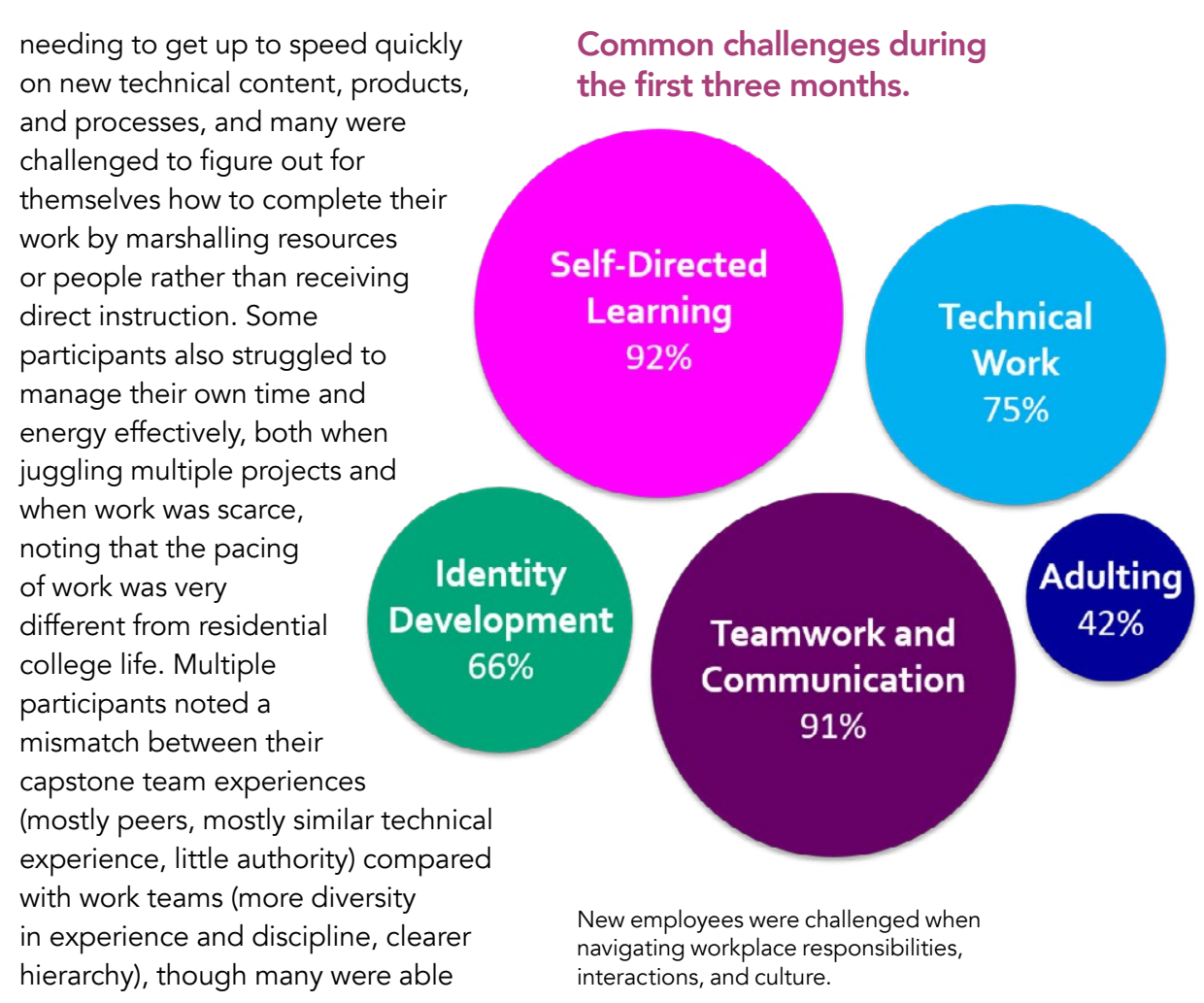

transfer their teamwork skills to th ewems ins in transferring their teamwork skills across contexts.

Strategies

articipants used multiple strategies to meet these challenges, the most common of which were talking to people and drawing on capstone desig perience. A recurring theme among participants was the critical role of 
Asking coworkers and supervisors questions proved an essential strategy confidence, and gaining a sense of belonging but also required significant navigation in choosing

Transfer from Capstone Capstone design was a dominant source of skills and strategies for participants. In particular, $85 \%$ of participants leveraged their capstone design experiences related to self-directed learning, and 74\% drew on teamwork and communication skills. These results are heartening, given that self-directed learning, teamwork, and communication are key components of capstone courses. Many of the new engineers also commented that capston woskplace, and that the experien had at work were just more complex or largerversions of capstone design, which significantly eased their

\section{IMPLICATIONS FOR CAPSTONE} EDUCATORS AND EMPLOYERS There is no single representative pathway for engineering graduates; participants' experiences highlight the sheer diversity of engineering work - design, troubleshooting, problemsolving, reviewing, field work, and more. New engineers describe engineering in different terms and their experiences resist binaries present in master narratives of engineering work. social versus technical, innovation
holistic versus narrow.

Because engineering work is so diverse, new employees are expected to be sefdirected learners, able to quickly grasp technical concepts as well as a company's culture and goals. Capstone design courses serve as critical preparation providing students with confidence to learn new things and strategies for building new knowledge. The courses provide authentic industry experiences through open-ended projects that place students out of their comfort zone. Through capstone design, students assimilate the knowledge they have gained in education, and use skills in a setting that requires professional attitudes and behavio Faculty teaching capstone design
Perceived preparedness by month.

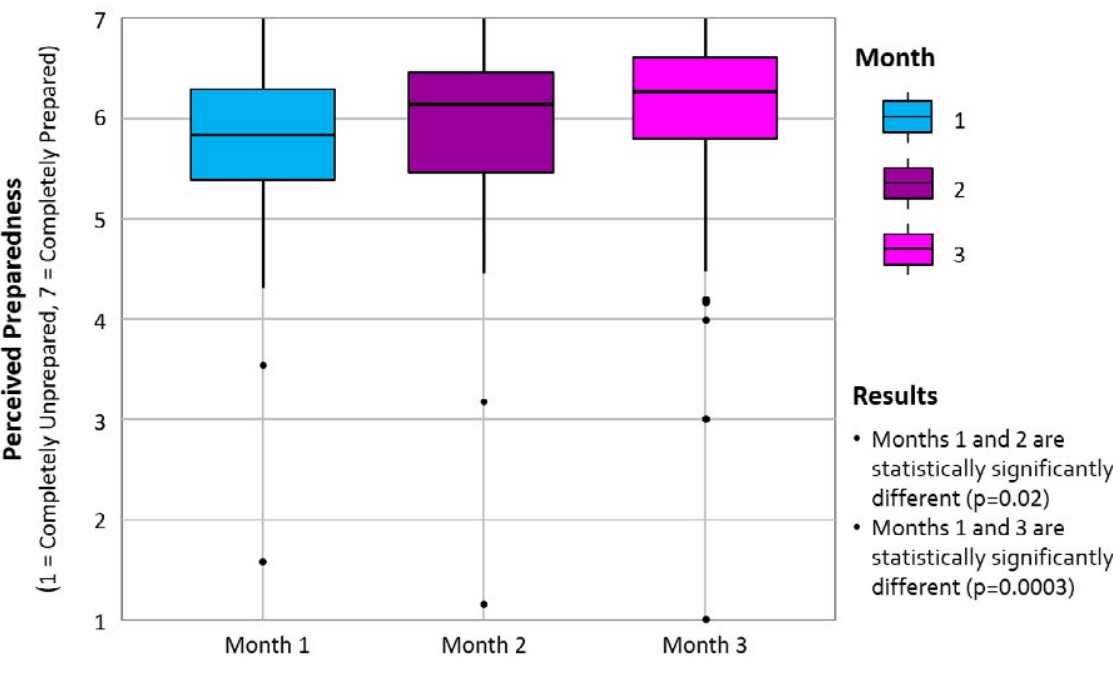

New graduates reported feeling well-prepared for ther
courses played an important role in this preparation.

self-directed learning through guided mentorship and modelling effective learning behaviours.

Additionally, new employees depend more on communication skills. Capstor and head home to familles and person courses - and even contemporary
couter work residential universities - cannot prepare students for the broader challenges

$85 \%$ of participants leveraged their capstone design experiences related to self-directed learning, and $74 \%$ drew on teamwork and communication skills.

design courses are a natural setting to seek to separate and balance their gain these skills, given their focus on developing personal lives with ther equipped with effective communication are better prepared to learn new skills from their colleagues and managers.

While capstone courses can help prepare new graduates for their first weeks and months working in industry. there are limits to the role these courses can play. For example, they will always struggle to replicate the range of experiences and ages present in professional settings. Similarly, while capstone projects can simulate some workplace challenges in terms of time pressures and competing demands, they cannot fully replicate the financi and business consequences found in industy or the time constraints
In short, regardless of their training in school, new graduates enter workplaces with steep learning curves where they perform activities and face situations they did not experience in school. Organisations hiring engineering facilitating successful school-to-work transitions by enculturating new employees and providing them with the training and resources necessary to help them activate and adapt their educational preparation, including capstone design. As such, academic preparation and industry onboarding act as partners to position new engineers for successt

\section{Behind the Research ก

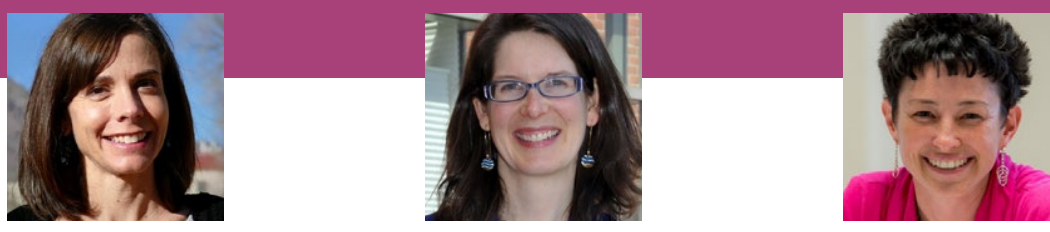

Marie C. Paretti Julie Dyke Ford Susannah Howe Daria Kotys-Schwartz E: capstone2work@gmail.com W: http://www.cchub2.org/links/c2w

\section{Research Objectives}

The Capstone To Work (C2W) research team studies students' experiences in the transition from capstone engineering desig courses to the workplace.

\section{Detail}

Bio
Marie C. Paretti is a Professor of Engineering Education at Virginia Tech. She holds a B.S. in chemical engineering and Virginia Tech. She holds a B.S. in chemical engineering and
an M.A. inglish from Virginia Tech and Ph.D. in English from the University of Wisconsin-Madison. Her research includes engineering communication, design education, engineering

Julie Dyke Ford is a Professor of Technical Communication and Mechanical Engineering at New Mexico Tech. She holds from the University of North Carolina at Charlotte, and Ph.D. in Rhetoric and Professional Communication from New Mexico State University. Her research includes engineering communication and knowledge transfer. Susannah Howe is the Design Clinic Director in the Picker Engineering Program at Signth College. She holds a B.S.E. in civil engineering from Princeton University and an M.Eng research includes engineering design education and capstone community building

Daria Kotys-Schwartz is a Teaching Professor in Mechanica Engineering and the Idea Forge Director at the University of Colorado Boulder. She holds a B.S. and M.S. in mechanica engineering from The Ohio State University and a Ph.D. in mechanical engineering from the University of Color learning, retention, and student identity development within engineering design.

Funding

Natinal Science Foundation.

Collaborators

Daniel Knight, Robin Ott, Nicholas Alvarez, Sidharth Arunkuma Tahsin Chowdhury, Jessica Deters, Christopher Gewirtz, Francesca Giardine, Cristian

[97 University of Colorado

smith college Vע VIRGinia

ow

\section{References}

Howe, S., Ott, R., Paretti, M. C., Herrandez, C., Deters, J. Gewirt, C., Giardine, F, Kary, A. (2019, June), Women's
Experiences in the Transition from Capstone Design Courses Experiences in the Transition from Capstone Design Courses
to Engineering Workelpaces Paparer presented at $2019 \mathrm{ASSEE}$ Annual Conference \& \& Exposition, Trampa, Florida. https:I/l peer.asee. org/33566.

Paretti, M. C., Kotys-Schwart, D., Ford, J., Howe, S., Ott, R. (2019, May). Process Matter(s): Leveraging the Design
Process to Build Self-Directed Learning. Paper presented at Process to Build Self-Directed Learning. Paper present
the 2019 Clive L. Dym Mudd Design Workshop.

Knight, D. W., Gewirtz, C., \& Chowdhury, T. M. (2019, July). The Impact of Capstone Design Courses on New Methods Investigation. In Research in Engineering Education Symposium. Cape Town, South Africa.

Howe, S., Rosenbauer, L. M., Ford, J.D., Alvarez, N. E.,
Paretti, M.C. Gewirt, C.. Kotys-Schwartz, D. A., Knight, D., Hernandez, C. (2018, June). Preliminary Results from Study Investigating the Transition from Capstone Design to Industry. Poster presented

Gewirtz, C., Kotys-Schwartz, D. A., Knight, D., Paretti, M. Deters, J., Hernandez, C. (2018, June). New Engineers' First Three Months: A Study of the Transition from Capstone Design Courses to Workplaces. Paper presented at the American Society for Engineering Education Annual
Conference and Exposition. Salt Lake City, UT. https://peer. asee.org/30838

\section{Personal Response}

What impact does this work have on you as capstone design educators, researchers, and students?

II This work reinforces for me, a capstone educator, the value of open-ended, applied design experiences in
preparing students for their careers. The struggles and preparing students for their careers. The struggles and
successes my students have during capstone design successes my students have during capst
will pay off as they enter the workplace.

II As a student, working on the C2W project has made me feel more prepared for life after college: what to expect

II The research findings help me to be intentional with each student interaction in capstone. Additionally, we are
able to inform our corporate partners what to expect as our alumni enter the workforce. 